\title{
TRANSFORMATION OF GEOSYSTEMS ON THE BAIKALIAN NATURAL TERRITORY
}

\author{
Tatyana Konovalova ${ }^{1,2}$, Alexander Sizykh ${ }^{3 *}$ \\ ${ }^{1}$ V.B. Sochava Institute of Geography, Siberian Branch of Russian Academy of Sciences, \\ 1 Ulan-Batorskaya St., Irkutsk, 664033, Russia; \\ ${ }^{2}$ Irkutsk State University, 664033 Irkutsk, 126 Ulan-Batorskay str., Russia; \\ 3*Siberian Institute of Plant Physiology and Biochemistry of RAS SB, 664033 Irkutsk, \\ 132 Lermontova str., Russia; \\ *Corresponding Author Alexander Sizykh, e-mail: alexander.sizykh@gmail.com;
}

Received June 2020; Accepted July 2020; Published August 2020;

DOI: https://doi.org/10.31407/ijees10.318

\begin{abstract}
The article considers the regularities of formation, development and transformation of geosystems. The text of the paper is an information synthesis of data and knowledge concerning the territory, drawings on V.B. Sochava's theory of geosystems, results from station-based investigations, cartographic information and on GIS technologies.
\end{abstract}

Key words: geosystems, organization, considers regularities, transformation, Baikalian natural territory. 